\section{The Abolition of Fibrillation}

In suitable cases abolition of fibrillation may be attempted by means of quinidine. This drug is a cardiac depressant, and may get rid of the circus movement in the auricle by increasing the duration of refractoriness in heart muscle. As it slows the rate of the circus movement at the same time these two effects may cancel one another, so that no beneficial effect is obtained.

When mitral stenosis is advanced, or there is evidence of myocardial damage in the senile type of case, quinidine is rarely successful, and is best not tried. Control with digitalis is the method of choice. If the accompanying lesions are but slight, and the heart is strong, it may be possible to abolish fibrillation. There is one type of case in which quinidine is usually successful-that in which the fibrillation persists without apparent cause. Some transient illness may have brought it on.

During the course of treatment the patient should be confined to bed. Quinidine sulphate may be given in 5 -grain doses in a capsule, or in an acid mixture.

R Quinidin. sulph. Acid. sulph. dil. Syr. aurant. ...

Aq. menth. pip.

$$
\begin{array}{lllll}
\cdots & \ldots & \cdots & \cdots & \text { gr. } v \\
\cdots & \cdots & \cdots & \cdots & m \mathrm{~m} \\
\cdots & \cdots & \cdots & \cdots & 3 \mathrm{j}
\end{array}
$$

A preliminary dose should be given first to ascertain whether the patient has any idiosyncrasy. If there is no headache, nausea, vomiting, or malaise the course may be completed. It is advisable to keep a chart of the apex rate, for there may be some rise after the first two or three doses. This acceleration is not likely to cause trouble if the patient is already under digitalis. After the preliminary dose further doses of 5 grains may be given every three or four hours until a normal regular rhythm has been resumed, or until 30 or 40 grains have been taken, or until the patient shows signs of intolerance. Some push the total dosage of the drug up to 60 grains or more. Another method of dosage is to prescribe 5 grains every two hours during the day for six doses, and repeat this again on two or three successive days. If quinidine is successful it usually acts after the first few doses. If normal rhythm is resumed it is wise to give 5 grains daily for a week or two in order to obviate any tendency for fibrillation to return.

\section{Auricular Flutter}

Auricular flutter differs from fibrillation in that the course of the circus movement is constant and regular. The rate of circulation is slower than in fibrillationusually about 320 . Ventricular response is regular as a rule, occurring at a definite ratio- 1 to 2 , or to 3 , or to 4 of the revolutions of the impulse of the auricle, with resulting rates of 160,106 , or 80 per minute.

Flutter is more likely to be associated with serious myocardial disease than is fibrillation. The age incidence is higher; it is more common in men than in women.

Digitalis. - The action of digitalis is similar to that obtained in auricular fibrillation, and the ventricular rate can be slowed. There is usually some difficulty in keeping the rate low, as there is always a tendency to increase to a higher ratio-from 1 to 4 (apex 80) to 1 to 3 (apex 106), or 1 to 2 (apex 160): a $1: 1$ ratio with an apex rate of about 300 is sometimes met with. As it result, the treatment of persistent flutter with digitalis is not so satisfactory as in fibrillation. It is often possible to transform flutter into fibrillation if full doses of digitalis are given, say 2 drachms of the tincture daily for three days to a patient weighing 10 stone. The rate at the apex falls, to a 1 to 4 ratio, and then may become completely irregular. This shows the change to fibrillation. If the digitalis is stopped a return to normal rhythm may result in a day or two, sometimes in a few hours. Some cases persist in fibrillation. They are better off than with flutter, as their apex rate is more easily controlled, and the sudden increases in rate are avoided. About 50 per cent. of cases of flutter can be changed to fibrillation. In about 30 per cent. of these there is return to normal rhythm.

Quinidine.-If the flutter persists in spite of digitalis quinidine may be administered as in a case of fibrillation. The circus movement may then be abolished, with a return of normal rhythm. Quinidine may also be used if digitalis has changed flutter to persistent fibrillation in the hope that normal rhythm may be resumed. The treatment succeeds in about 30 per cent. of cases. Heavy doses of quinidine, such as may be needed, should not be given when the heart is grossly diseased or near to failure. The patient should stay in bed while the abolition of flutter is being attempted.

Life and Occupation.-Patients with persistent auricular flutter need to lead a very restricted life. The heart is usually the seat of considerable disease. The apex rate is difficult to control. Digitalis must be given continually on the same lines as for a case of persistent fibrillation.

\section{A PAIR OF SPECTACLES}

BY

\section{J. D. M. CARDELL, F.R.C.S.}

The date when the first pair of spectacles was made has not been established beyond doubt. It has been stated that the Chinese at one time used bleached horn from which lenses were fashioned, while Nero is said to have used a precious stone mounted in a ring, through which he watched games in the circus. This may have been a lens, or merely a tinted protection against over-strong light. In a fourteenth century manuscript in the B:bliothèque Nationale in Paris there is a picture of St. Paul using a pair of spectacles. Marco Polo records that, when travelling in China in 1270 , lenses ground from quartz or semi-precious stones were being used as an aid to sight. So much for the more nebulous historical evidence.

\section{From the Thirteenth Century Onwards}

In 1276 Roger Bacon refers to the possibility of glass lenses being used by those who are old and have weak sight. Spina, a Dominican friar who died in 1313, and is generally considered to be the inventor of spectacles, probably exploited Bacon's idea, though there is a tomb in the Church of St. Maria Maggiore with the rather naive epitaph:

"Here lies Salvino d'Armato of the Armati of Florence, Inventor of spectacles. God pardon him his sins. A.D. 1317."

Salvino may, however, have merely popularized Spina's "invention."

The date is therefore fairly certain as regards the first use of spectacles in Europe. The original type was a single magnifying glass with a short handle ; another lens was then placed in the opposite end of the handle with a hinge in the middle so that both eyes might be assisted. There are numerous references, which need not be cited here, to the use of spectacles in the thirteenth and fourteenth centuries, Bernard Gordon, professor of medicine at Montpellier in about 1305 , being the first physician to refer to them. The introduction of printing probably increased the demand for spectacles.

The lenses were first made of tourmaline, beryl, quartz, and later of glass. The glass employed was primarily produced in Venice, but subsequently its manufacture extended to Germany. The first German frames were 
made of leather, the bridges being reinforced with fishbones. At a later date strings looped over the ears were used to steady the glasses. (One still meets this method employed as a first-aid measure to broken frames!) Side pieces of metal were next introduced, and glasses with frames of iron, brass, and copper were sold in London during the eighteenth century for 1s., a pair with gold frames costing between $£ 10$ and $£ 20$. The lenses were circular, but ovals were in vogue in the early part of that century. At the beginning of the Georgian period tinted glasses were used as a protection against strong light. Tortoise-shell frames date from the reign of George III. Steel frames again came into favour, especially at the end of the nineteenth century, to be followed by the rimless type of spectacle. "Bifocals" were, of course, first introduced by Dr. Benjamin Franklin at the end of the eighteenth century.

\section{Spectacles of the Present Day}

It will thus be seen that there has been ample time in which to perfect glasses and their fitting, but it is sad to have to admit that not all spectacles made to-day are an improvement on some of the crude forms of the seventeenth century. That this state of affairs still exists is due to the marvellous tolerance of the eyes, and the fact that they are inarticulate-or perhaps one might say that their complaints are often aired by parts of the body remotely situated, and therefore remain unrecognized as signs of eyestrain. Furthermore, there is a sad ignorance-even amongst well-educated people-of the importance of glasses accurately prescribed and properly fitted and made. Such people are quite prepared to choose glasses from a tray in a store. In such spectacles both lenses are usually supposed to be of the same strength, irrespective of the fact that it is comparatively rare for both eyes to be of exactly the same refraction (just in the same way it is rare for both arms to be of the same length or both sides of the face to be symmetrical).

\section{Manufacture of Lenses}

The exact composition of the glass of each manufacturer is a jealously guarded secret. Suffice it to say that the glass used in spectacles has little or no lead in it, so that splinters entering the eye or orbit are not opaque -as is, for instance, some bottle glass-to $x$ rays. Quartz, which was used for the " pebbles" of the past generation, lacks homogeneity, and gives a lens whose power varies from one point to another. It has now been superseded by glass.

The glass for optical purposes differs from that used for other instruments such as microscopes or cameras. The essential ingredients are silica (white sand or ordinary sand) and a suitable base, such as sodium carbonate. Sometimes lime or boric acid is added. Crown glass or soda-lime glass is most commonly used. Flint glass or a potash-lead glass is very fusible, easily worked, and, having a high refractive index, is employed for the reading segment of bifocal lenses. In preparing crown glass for optical purposes a cylinder is blown on a " blowing iron." Th:s is cut longitudinally with a diamond and rolled out flat on a heated stone slab. Disks of an appropriate size are cut and are known as "blanks."

Special tinted glass is sometimes required. As a rule this is obtained by adding 6 per cent. of titanium dioxide and nitre, or 1 per cent. of a h:gher oxide of vanadium, with or without nitre, together with manganese dioxide, cobalt, nickel, or uranium oxides. Of the best-known tinted glasses "Crookes A" transmits 86 per cent. of daylight, "Crookes A 2 " 78 per cent., "Crookes B" 46 per cent., and "Crookes B 2 " 20 per cent.

\section{Faults in Optical Glass}

There are several faults which may be present in optical glass' and render it unsuitable for optical purposes. In testing the quality of various types of glass for spectacles the coefficient of cubical expansion is most important. This should be as small as possible in order to eliminate the risk of breakage due to temperature changes. A firstquality glass is water-white; the refractive index of crown glass is 1.5 and of flint 1.58 . These indexes must be constant. A baryta boron-s:licate glass is considered in the first class, a zinc or alumina base free from alkali second, and a soda-lime alkali third.

Some of the faults may be detected in the "blank" state, while others may only be discovered after grinding has commenced. The former are exemplified by bubbles, colourless striae, and green colour; an example of the latter is the appearance of cracks indicating strain in badly annealed glass. The faulty grinding or polishing of the "blank" may make the glass unfit for use, by causing surface waves, inaccuracy in strength, greyness, and holes. Good lenses do not vary in strength from the ophthalmic surgeon's prescription by more than 0.06 dioptre. Cylinders must furthermore be accurate as to axis within 0.5 degree, and the optical constants of all lenses must be 95 per cent. true.

Cheap mass-production lenses are frequently ground from defective blanks for too long or too short a time, and so tend to exhibit many of the defects mentioned. Since lenses are graded according to the presence or absence of these defects, it is obvious that there are many grades of lenses, the better of which are used in more expensive spectacles. It is practically impossible to obtain a good-grade lens at the cost at which some glasses are offered. It should be remembered that it takes men of vast experience, who do nothing else, to eliminate faulty lenses. It is thus hardly to be expected that a mass-produced spectacle can approach that provided by the optician who concentrates only upon the making of glasses. Thus the finished lenses supplied by one foreign firm were such that about 75 per cent. had to be rejected by a well-known optician.

\section{Grinding of Lenses}

In the better type of spectacle each lens is ground individually under the constant care of a skilled workman with a knowledge of the size of rim or " eye " into which the lens is to be inserted. In mass-production lenses a large number are ground at one and the same time. In any such batch lenses of all grades are to be found after grinding, for, though they need not vary as to power, there are often considerable differences in quality and finish. Grinding is effected with the help of progressively fine emery, while polishing is done with a tool covered with felt suitably treated with wax and fed with rouge (iron oxide) and water. The best lenses are polished on wax only, as distinct from cloth impregnated with wax. This, of course, involves longer time, and is an unsound commercial proposition if cheap lenses are to be supplied.

The individually ground lenses are very carefully centred, and then cut so that their optical centres correspond to the patient's interpupillary distance, no matter what size of frame is demanded by the future wearer's face. In this respect it is important to note that the same individual's interpupillary distance will vary when he is looking in the distance, reading mus: $c$, and reading print ; due allowance for this must be made in the finished spectacles. Thus is ensured an accuracy which can never be a certainty with mass-produced lenses " out of the box " fitted to frames " off the shelf." 


\section{Frame Making}

The making of a reliable frame is a difficult but interesting process. Good steel frames are made by hand, from grooved steel strip and steel wire. They are constructed to fit individual facial measurements, whereas those produced en masse are made in sizes each differing from the next by a standard amount-for instance, the difference in width between one size and another is usually $2 \mathrm{~mm}$. Since the nature of this type of frame allows of very little adjustment, there is room for what a competent worker would regard as a fairly gross error. The cheaper tortoise-shell frames are made not from the solid shell but from flakes cemented and pressed together. Unless exceptional care is taken, the slightest amount of grease between one layer and another will lead to eventual cleavage in that plane. The better shell frames are cut out of the solid shell, and by treatment in boiling brine are moulded to the exact shape required by the purchaser's face.

Each particular frame is made with the purpose for which it is to be used in view, and frequently many fittings on the face and minor adjustments are required before perfection is attained. A good pair of spectacles will balance evenly on a pencil placed under the bridge, irrespective of any difference in strength of the right and left lenses. This is made possible by special grinding. Not everyone can wear tortoise-shell frames, since they are unsuitable where a narrow interpupillary distance is coupled with a wide nose (and vice versa) and in small faces generally. The pad bridge is unsuitable where the interpupillary distance is wide and the bridge of the nose narrow, and with asymmetrical faces.

To a certain extent these difficulties can be overcome by individual grinding, so that the optical centres-that is, the point in the lens at which no prismatic displacement of image takes place (and this is not necessarily in the centre of the lens)-are decentred away from the geometrical centres. This is only advisable in the better-class frames, where rotation of the lenses is rendered impossible by some locking device. Should such lenses need repair the spectacles must be returned to the original maker to ensure correct decentring of the new lens. In the case of asymmetry it is generally better to have the frame itself made asymmetrically.

\section{Fitting of Spectacles}

There is a well-defined technique required in the proper fitting of frames, and this technique, the laws of which are perfectly understood by properly trained opticians, has to be practised assiduously for many years before conscientious fitting can be undertaken. The many and various problems presented by the diversity of human eyes and of their requirements cannot be solved by simply attending a course of lectures and passing an examination. The accurate fitting of the optical centres of the lenses to an interpupillary distance which varies with the different activities of the eyes, and the moulding of the frame to facial asymmetry are two of the very simplest problems to be confronted. The height of the optical centres from the lower margins of the lenses in respect of each other must be suited to the purpose for which the glasses are ordered.

The optical effect of moderately strong lenses which have to be displaced forward owing to the particular formation of the bridge of the nose or of the lashes, or as a result of exophthalmos, provides a more complicated problem. The frame must therefore be an individual fitment, which is not only the most comfortable to the patient and suits his aesthetic taste, but, what is of the greatest importance, holds the lenses in such a position that the final optical effect is perfect for the particular purpose in view after the desiderata considered above have been satisfied. Thus different fittings are required for constant or general wear, distance, music, reading print, jewel setting, etc., and the fitting for one purpose might, in any individual case, be harmful if used for another.

Besides being a technician, the fitter must also be an observant student of psychology. It would be foolish to give a heavy-handed person a delicate rimless frame, even though he might desire it. Again, in the case of a woman, the type of hat worn must be considered. Tight-fitting hats often press the sides of the frame uncomfortably into the head, and certain forms of ha:dressing preclude frame-sides which curl round behind the ear. An impatient, highly strung person may wish for folding spectacles, but it is soon realized, after watching him handle a pair, that it would prove a constant source of annoyance, and an unwise type of frame to recommend. In the same way it is a physical impossibility for some people to put on pince-nez at the identical angle twice consecutively. Where the lenses are not weak spheres, or where there is any correction for astigmatism, the oculist's prescription is altered every time they are placed on the nose.

\section{Ill Effects of Inferior Glasses}

In order to reduce the cost of glasses and to effect rapid repairs or delivery, the frames may be of stock size and the lenses may be of poor quality glass, their power being inaccurate. The position of high-powered lenses (such as in cataract) may give an effective strength entirely different from that arrived at by the oculist in the trial frame, and the optical centres may be misplaced.

Ill-fitting frames, especially in the case of children, may cut the nose badly, or chafe the auricular furrow at the back of the ears. The cheaper imitation shell frames are influenced by the heat and moisture of the head, the sides tend to open, and though snugly fitting at first, become, after a time, too loose. They may continually slip down the nose, or may fall off and break. Again, in poor frames the lenses may rotate-a serious occurrence when the lenses have been decentred, or where there is a cylindrical correction.

Pcor quality lenses will scratch easily, show chromatic aberration, and have a wavy surface. Such lenses will not give the eyes the necessary relief. Furthermore, the centres may be displaced. When this results in one centre being higher than the other, a false hyperphoria is produced which will give rise to marked eyestrain. Another frequent fault is where the centres of reading glasses are too wide apart. One sees numbers of cases in which this fault, increasing the amount of convergence required, leads to tiredness, headaches, and finally inability, to read. This fault is very commonly found in bifocals supplied by inexperienced opticians.

Unfortunately many lay people think they know what is best for their eyes. Two examples may be given of this. There have been numerous cases where a patient, having found that the vision is getting poor with glasses which have been in use for some time, requests that the " next strength" be supplied without a surgeon's prescription. Unhappily this is sometimes acceded to, and a stronger glass which brings the vision up to something like normal is provided. Later-frequently too late-it is found that the dimness of vision was not wholly due to lack of strength of the glass, but to an insidious disease such as glaucoma. Secondly, the hypermetropic patient will sometimes refuse to wear prescribed glasses, 
because the ciliary muscles, having got into a state of spasm through the non-use of glasses or the use of too weak a correction, will not at first relax and allow the glasses to do the focusing which they have got into the habit of doing for themselves.

The oft-repeated phrase of the late Mr. J. H. Fisher comes to my mind, "I did not give you those glasses to see with." I have seen a patient with bad headaches wearing minus 3 dioptre spherical lenses obtained from a shop when plus 1 dioptre spherical was required. The reason for the choice of these lenses was that, in most cases, an emmetropic eye can get a clearer though smaller image when a minus lens is placed in front of it. It is not always a case of prescribing the glass with which best vision is obtained.

There were once machines, on the penny-in-the-slot principle, where anyone requiring glasses looked through binocularly adjustable telescopes at some print, when, by turning knobs the print was focused to the victim's entire satisfaction, a button was pressed and the "correct" prescription printed on a neat card fell out of the machine. Fortunately this particular type of horror has vanished.

\section{Conclusion}

The eye and its well-being is a precious asset. How precious can only be fully appreciated by those who are irrevocably becoming blind. Because the eyes are so efficient, adapting themselves so remarkably to all forms of adverse conditions and abuse, we are rather apt to treat them thoughtlessly, forgetting that in so many cases too much may be expected of them. As we are only granted one pair of eyes to last a lifetime, and that, once lost, no form of artificial eye will be of any visual use, it obviously behoves us to treat thern fairly, and to be certain that nothing but the best be provided for their use. A poorly conceived and made " aid " to vision may in the end prove more disastrous than none at all. Those who have the preservation of the sight of their fellow beings in their care should therefore be able to differentiate between what is good and what is harmful to the health of the eyes.

\section{BIBLIOGRAPHY}

Thompson, C. J. S. : "The Origin and Development of Spectacles," The Connoisseur, October, 1934

\section{MEDICINE AND THE EMPIRE}

\section{B.M.A. LUNCHEON IN LONDON}

At the invitation of the Officers of the British Medical Association a luncheon party was held in London at Grosvenor House on June 27th, when the principal guests were Mr. G. M. Huggins, F.R.C.S., Prime Minister and Minister for Native Affairs, Southern Rhodesia ; Colonel the Hon. Herbert Bruce, F.R.C.S., Lieutenant-Governor of Ontario, and Mrs. Bruce ; the Hon. Sir Stanley Argyle, M.B., late Premier, Treasurer, and Minister for Health, Victoria ; Sir Harry Batterbee, Assistant Under-Secretary of State, Dominions Office ; and Sir Thomas Stanton, Chief Medical Adviser to the Secretary of State for the Colonies. The guests were received by Dr. E. Kaye Le Fleming (Chairman of Council) and Mrs. Le Fleming, and Dr. S. Watson Smith (President of the Association).

After luncheon Dr. Le Fleming, extending a warm welcome to those present, said that the Council had long felt its disadvantage in having no official means of paying honour to important members of the profession from over-seas who passed through the metropolis. This luncheon party gave an opportunity to repair the defect in an informal way during the visit of Mr. Huggins, Colonel Bruce, and Sir Stanley Argyle. To Sir Harry Batterbee and Sir Thomas Stanton the Association owed a particular debt for their help in the arrangements for the forthcoming Round-the-world Tour to Australia. Dr. Le Fleming recalled with pleasure that Mr. Huggins had been chairman of the Mashonaland Division of the B.M.A. for a number of years and in that capacity attended the Annual Meeting at Edinburgh in 1927. He assured Colonel Bruce that all who went to the Winnipeg meeting in 1930 had a lively recollection of Canadian hospitality, while many of those present looked forward to meeting again next September in the State of Victoria, of whose Government Sir Stanley Argyle had been the head.

Mr. Hugariss, in acknowledging the toast, said how much he valued the opportunity of meeting distinguished members of his own profession. It was always his wish to keep contact with practice, his first love. This informal friendly gathering came as a pleasant contrast to large official functions. Colonel BRUCE expressed his keen pleasure at meeting old medical friends and making new ones. Like Mr. Huggins, he also had to "lead a double life" and perform in public life many operations which were unknown to surgery. Speaking of his happy memories of past B.M.A. Annual Meetings, Colonel Bruce paid tribute to the wonderful influence of the Association, both in the medical profession and in the wurld at large, through its 35,000 members with Branches throughout the Empire. The Jubilee broadcast on May 6th had brought home to all the solidarity of the British peoples. They heard " London calling" one part of the Empire after another, and then-most thrilling moment-the King's voice. Sir Stanley ARgYle expressed to the parent body the gratitude of the Victorian Branch for the privilege of receiving the B.M.A. in Melbourne during the celebration of the hundreth year of that State. Victoria was British through and through, and felt it a signal honour to entertain the B.M.A. Small gatherings such as this in Grosvenor House, and large gatherings such as they looked forward to in Melbourne, kept the life blood of the Empire circulating. It was, he said in conclusion, a happy and valuable thing for members of the great scattered family to meet and know each other. Upon this note a very enjoyable and successful party ended.

The company present included, besides those whose names are given above: Mr. H. S. Souttar (Chairman of Representative Body, B.M.A.), Mr. N. Bishop Harman (Treasurer B.M.A.) and Mrs. Bishop Harman, Sir Henry Brackenbury (late Chairman of Council and Vice-President B.M.A.) and Lady Brackenbury, Dr. C. O. Hawthorne (late Chairman of Representative Body and VicePresident B.M.A.), Dr. W. Paterson (Chairman, Dominions Committee, B.M.A.) and Mrs. Paterson, Lord Dawson of Penn (President, Royal College of Physicians of London and Vice-President B.M.A.), Sir Holburt Waring, Bt. (President, Royal College of Surgeons of England), Sir Humphry Rolleston, Bt. (Vice-President B.M.A.), Dr. Alfred Cox (Vice-President B.M.A. and late Medical Secretary), Dr. Robert Hutchison (President, Royal Society of Medicine and President of the Section of Diseases of Children, Melbourne Meeting, B.M.A., 1935) and Mrs. Hutchison, Dr. J. S. Fairbairn (President, British College of Obstetricians and Gynaecologists, and President, Section of Obstetrics and Gynaecology, Melbourne Meeting, 1935) and Mrs. Fairbairn, Sir Thomas Dunhill (member of the Council, B.M.A., and President, Section of Surgery, Melbourne Meeting) and Lady Dunhill, Sir George Badgerow and Lady Badgerow, Mr. W. Rowley Bristow and Mrs. Bristow, Dr. G. C. Anderson (Medical Secretary, B.M.A.) and Mrs. Anderson, Mr. L. Ferris-Scott (Financial Secretary and Business Manager, B.M.A.) and Mrs. Ferris-Scott, Dr. N. G. Horner (Editor, British Medical Journal) and Mrs. Horner. 